\title{
Gradually including potential users: A tool to counter design exclusions
}

\author{
Emilene Zitkus*, Patrick Langdon, P. John Clarkson \\ Engineering Design Centre, Department of Engineering, University of Cambridge, Trumpington Street, Cambridge CB2 1PZ, Cambridgeshire, United Kingdom
}

\section{A R T I C L E I N F O}

\section{Article history:}

Received 21 June 2016

Received in revised form

2 May 2017

Accepted 23 July 2017

Available online 29 August 2017

\section{Keywords:}

Ergonomic task demands

Design practice

Inclusive design tool

Design for all

Universal design

\begin{abstract}
A B S T R A C T
The paper describes an iterative development process used to understand the suitability of different inclusive design evaluation tools applied into design practices. At the end of this process, a tool named Inclusive Design Advisor was developed, combining data related to design features of small appliances with ergonomic task demands, anthropometric data and exclusion data. When auditing a new design the tool examines the exclusion that each design feature can cause, followed by objective recommendations directly related to its features. Interactively, it allows designers or clients to balance design changes with the exclusion caused. It presents the type of information that enables designers and clients to discuss user needs and make more inclusive design decisions.
\end{abstract}

() 2017 Published by Elsevier Ltd.

\section{Introduction}

Independent living is a topical issue as many societies are coping with ageing populations (UN, 2011). For example, in the United Kingdom it is expected that by 2035 around $23 \%$ of the population will be aged over 65 (ONS, 2012). This demographic change means a sharp increase in the older adult product and service market sector. However, compared to the other age groups, the older adult market segment is likely to have a greater number of people with physical, sensorial and cognitive disabilities (WHO, 2011). In fact, in Europe, on average, the disability prevalence among people aged 65 and over is four times higher than people aged 15 to 44 and two times higher than people aged 45-64 years (Eurostat, 2015). Similarly, in the USA more than $38 \%$ of people aged over 65 reported having at least one type of disability, which is the age group with the highest incidence of disability (He and Larsen, 2014). A recent survey conducted in England demonstrated that, on average, the quality of life of people aged over 64 years decreases due to disabilities affecting individuals' locomotion, dexterity, vision, hearing, memory, and other capabilities (ONS, 2014).

In analysing previous studies Karlsson (2013 - p.213) stated that

\footnotetext{
* Corresponding author. UNESP, University of São Paulo State, Av. Eng. Luiz E. C. Coube, 14-01, 17033-360, Bauru, Brazil.

E-mail addresses: emilenezitkus@gmail.com (E. Zitkus),pml24@eng.cam.ac.uk (P. Langdon), pjc10@eng.cam.ac.uk (P.J. Clarkson).
}

products generally target younger able users, and as a result, "older users have to cope with technology that does not meet their more fundamental needs", causing them extra difficulties. These difficulties reinforce the case that "if something is both less useful and less pleasurable in practice, then people are understandably less inclined to engage with it" (Selwyn, 2004). Thus, unless the needs of older adults and people with disabilities are integrated into design processes, new designs will not meet these needs or, in turn, promote independent living.

The research presented here recognised that inclusivity can be a challenge for designers. Addressing inclusivity issues during product development means that designers should be aware of the diverse range of capabilities in the population. However, the connection between design features and the end-users' physical, sensorial or cognitive capability is not easily identified (Persad et al., 2007). Furthermore, the relationship between the skills required by design features and their impact on different levels and types of capability loss readily identified is not simple to understand (Tenneti et al., 2012; Johnson et al., 2010). Thus, it is necessary to facilitate the linkage between design features and the potential exclusion they may cause.

For instance, the interaction with controls with small switches (or sliding buttons or pressing buttons) placed close together requires precise grips that are difficult to be performed by people with dexterity problems, such as arthritis or Parkinson's disease. In other cases, there are innumerable products and packages that use 
text fonts or foreground and background colours that are illegible for people with vision loss, whether it is a result of macular degeneration, glaucoma, cataracts, colour blindness, short sightedness or other disability. In these cases, the design feature itself causes the exclusion of a portion of the population.

Nevertheless, the research recognised that product development is complex and design elements are interconnected, which compromises design decisions. For example, the text size in a product may be related to the size of the product, which may be related to the reduction of materials which classifies it as a sustainable product. However, even in such a case, balancing design requirements with design changes informs design decisions. Thus, despite those major limitations, product developers could gradually include small changes in their designs. As an example, having the option to change the text font, text colour or background colour to make a final product more accessible and usable would not necessarily affect other project specifications. The mobile phones and the remote controls in Fig. 1 are some examples where small changes could result in a more legible and usable product for a wide range of users without necessarily affecting other design attributes. The text size, colour and foreground-background colour in the mobile phones make the mobile on the right more legible and ease of use. The option of having reduced functions (or hidden functions in the slide cover) and higher colour contrast make the remote control on the right simpler and more legible.

In the same way, in Fig. 2, the toaster, the coffee maker, the telephone and the camera could all increase the colour contrast of their labels for more legible ones. In these cases, product developers could have been informed about the design exclusion, enabling them to make changes while it was still possible during early stages of the design process, thus making such changes less expensive.

\subsection{Inclusive design tools}

The need to enable product design teams to understand the end-users' requirements has driven experts to develop an extensive range of techniques for many years. However, according to Goodman et al. (2006a and 2006b), one of the barriers to inclusive
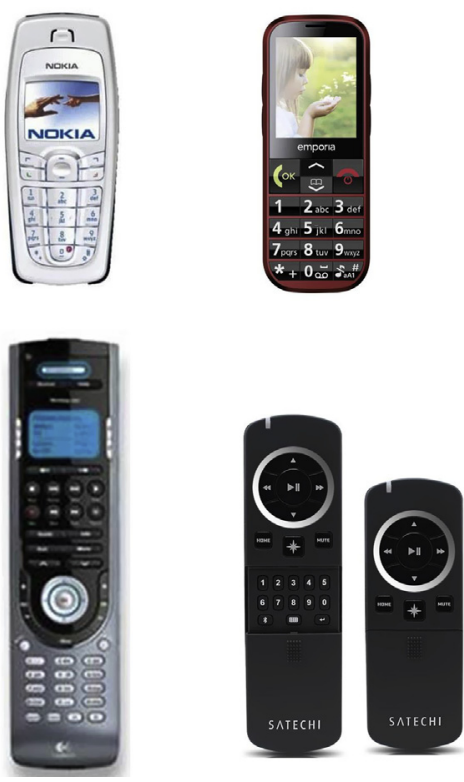

Fig. 1. Comparison of similar products: on the right, examples of design attributes favouring the legibility of mobile phones and remote controls. design adoption is the incompatibility between the techniques and design practice in industry. In this paper, the tools are measured according to three major aspects presented in the literature that influence their use or lack of use:

1. Integration to process: the earlier a product meets user requirements, the less the changes impact the process (Clarkson et al., 2007). Assessing new designs while they are created during the conceptual phase - have minimum effect on the project's budget, the project's plan and the design activity (Ulrich and Eppinger, 2008).

2. Interface of design evaluation tools: visual interactive interfaces with graphical information, like simulations, images, or animations are described as the best way to communicate with designers (Macdonald and Loudon, 2007; Porter and Porter, 1999; Henderson, 1999).

3. Effective results: quantifiable data directly related to design issues rather than human characteristics can be more effective and efficient (Happee and Wismans, 2009; Burns et al., 1997). In a study conducted by Dong et al. (2003 - p.116) the designers underlined that exclusion numbers could help to persuade clients to invest in inclusivity. Thus, another requirement is that results have to persuade not only designers, but also clients. As indicated in past studies, both clients and designers make design decisions and they need information that satisfies their interests (Cornish et al., 2015; Goodman-Deane et al., 2010; McDonnell and Lloyd, 2009; Le Dantec and Yi-Luen Do, 2009; Goldschmidt and Eshel, 2009; Oak, 2009).

The available inclusive design techniques vary in format and scope, including, among others, guidelines, user tests and physical or virtual simulation tools (Zitkus et al., 2011; Zitkus, 2017). They are briefly described below, while their integration to process, interface and results provided are outlined in Table 1.

\subsubsection{Guidelines}

Standards and guidelines have been suggested by many experts as a way to guide designers to address the needs of end-users (Nicolle and Abascal, 2001). A broadly acknowledged example is the World Wide Web Consortium (W3C), which has developed standards and guidelines for designing accessible websites (Brajnik et al., 2012). The main difference between guidelines is their scope; some of them cover general requirements, whilst others cover specific information. The type of information presented influences the stage in the process where it could be applied (as shown in Table 1), which is directly related to its integration to design processes (Burns et al., 1997).

\subsubsection{User tests}

Direct user participation in the design process is a well-known way to enable designers to understand user needs and develop empathy with them (Sanford et al., 1998). Involving older adults and people with disabilities is beneficial as the outcomes show product problems related to a diverse range of users, which supports inclusive design (Cassim and Dong, 2015; Wilkinson and De Angeli, 2014). Methods where end-users are involved include usability tests (Norman, 2013), user observation (Eisma et al., 2004), user co-designing (Rode et al., 2004) and, user theatre (Newell et al., 2006). However, the value of user-centred techniques is often undermined by the time needed to recruit and select a representative sample of users, added to the time for data collection and analysis (Marshall et al., 2015). In addition, concerns about ethical issues, such as the vulnerability of elderly or disabled people, are often cited by industry as reasons to not engage in this technique (Newell et al., 2006; Dong et al., 2003). As a result, user 

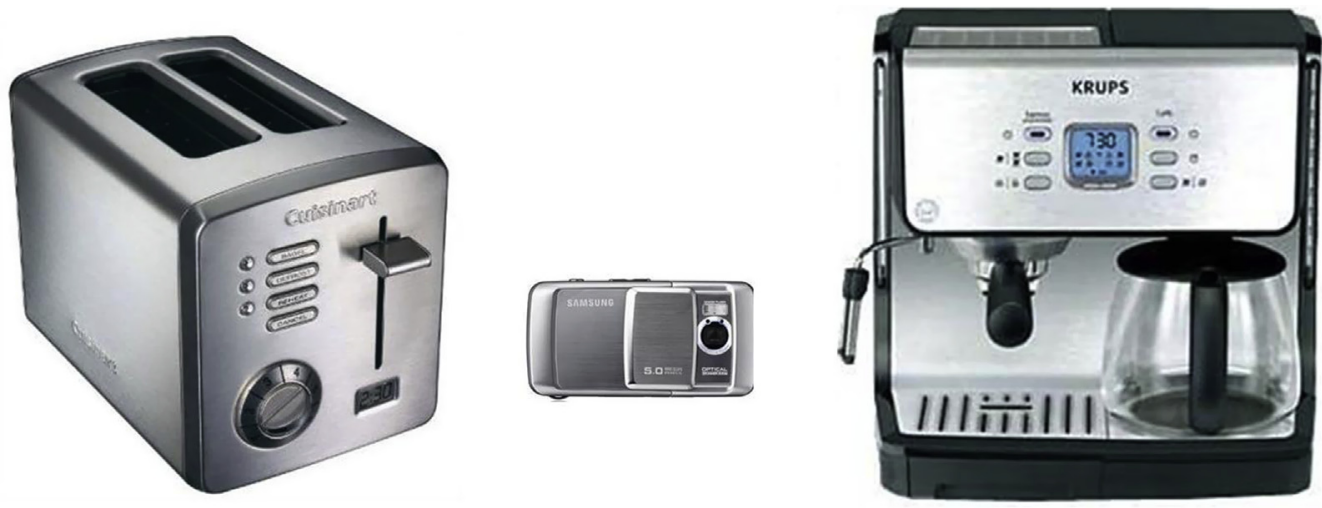

Fig. 2. Some products that could benefit from small changes in favour of legibility and ease of use.

Table 1

Integration, interface and results of inclusive design evaluation tools.

\begin{tabular}{|c|c|c|c|}
\hline & Process integration & Interface & Results \\
\hline Generic Guidelines & Early in the conceptual phase & Generic information in texts and tables format. & Non-specific results. \\
\hline Specific Guidelines & During the conceptual phase & $\begin{array}{l}\text { Objective information in texts and tables format } \\
\text { that can be used as checklist. }\end{array}$ & $\begin{array}{l}\text { Specific results related to the product under } \\
\text { development. }\end{array}$ \\
\hline User-centred techniques & $\begin{array}{l}\text { Early in the conceptual phase, through } \\
\text { similar } \\
\text { products, or later through rapid }\end{array}$ & $\begin{array}{l}\text { Observation of real users and/or their feedback } \\
\text { after the trial. }\end{array}$ & $\begin{array}{l}\text { Inspiring. Exclusion is not quantifiable. Re- } \\
\text { assessing the product is an issue due to sample } \\
\text { selection. }\end{array}$ \\
\hline Third-Age Suit/Age Explorer & prototypes. & $\begin{array}{l}\text { Designers observe themselves with physical } \\
\text { restrictions. }\end{array}$ & $\begin{array}{l}\text { Inspiring. Exclusion is not quantifiable. } \\
\text { Re-assessing the product means wearing the }\end{array}$ \\
\hline Simulation Toolkit & & $\begin{array}{l}\text { Observation of themselves with different levels } \\
\text { of restrictions. }\end{array}$ & suit again. \\
\hline HADRIAN & During the conceptual phase & $\begin{array}{l}\text { Visual interaction with user avatars } \\
\text { integrated to CAD software. }\end{array}$ & $\begin{array}{l}\text { Quantifying exclusion is limited due to the } \\
\text { range of tasks and the user database. }\end{array}$ \\
\hline VERITAS project & & & Exclusion could be quantifiable with a broad \\
\hline VICON project & & $\begin{array}{l}\text { Visual interaction, integrated with CAD } \\
\text { software. }\end{array}$ & $\begin{array}{l}\text { anthropometric and capabilities database. The } \\
\text { sample size however is not publicly available. }\end{array}$ \\
\hline INCLUSIVE CAD & During the conceptual phase & $\begin{array}{l}\text { Visual interaction with informative simulation } \\
\text { of muscles, hip and knee joints. }\end{array}$ & $\begin{array}{l}\text { Quantifying exclusion is limited due to the } \\
\text { range of tasks and the focus on physical } \\
\text { capabilities. }\end{array}$ \\
\hline Impairment Simulator & & $\begin{array}{l}\text { Visual interaction with simulation of some } \\
\text { vision and hearing capability loss. }\end{array}$ & $\begin{array}{l}\text { Quantifying exclusion is limited due to the focus } \\
\text { on sensorial capabilities }\end{array}$ \\
\hline Exclusion Calculator & Any time through task analyses. & $\begin{array}{l}\text { Visual interaction with a range of applicable } \\
\text { tasks. }\end{array}$ & $\begin{array}{l}\text { Calculates the exclusion percentile of the UK } \\
\text { adult population. }\end{array}$ \\
\hline
\end{tabular}

tests with the elderly and people with disabilities are rarely adopted in industrial contexts.

\subsubsection{Physical simulations}

The simulation of physical capability loss by wearing apparatus helps young, able-bodied people understand the limitations caused by physical impairments (Moore, 1985). Some recent versions of this type of tool include Third-Age Suit (Hitchcock and Taylor, 2003), Age Explorer (Meyer-Hentschel, 2007) and Simulation Toolkit (Cardoso and Clarkson, 2007). All of these tools have braces, pads, and other physical restrainers sewn into the suit. They also have fogged or yellow spectacles to limit vision and, in some cases, earmuffs to decrease the wearer's hearing capability. In all these three simulation tools the outcomes can be inspiring, but they may not reflect how someone with reduced capability would interact with a product. The results rely upon the way the task is simulated and the problems prioritised, which are based on designer's assumptions and can produce erroneous assessments. Coping strategies, for instance, can occur when the product demand exceeds the individual's capability, and thus, unexpected actions are taken to cope with the task requirements (Persad et al., 2007 p.131). Therefore, even experienced practitioners might not reflect real users' performances; whereas in user-tests the problems are prioritised according to user's assessment, which gives a more precise result based on their needs instead of the designer's assumptions.

\subsubsection{Virtual simulations}

The intention of virtual tools is to evaluate the impact of interactions before further developing new designs. These computerbased tools are integrated into CAD models, which enable design teams to assess new concepts during the conceptual phase - early in the process. These types of inclusive design tools are HADRIAN (Hussain et al., 2016), VERITAS, VICON (Kaklanis et al., 2013) and INCLUSIVE CAD (Macdonald et al., 2007). Other virtual tools are the Impairment Simulator (Clarkson et al., 2013) and Exclusion Calculator (Goodman et al., 2014) which explore the capability loss related to some impairments and the level of functional loss (the severity). The Impairment Simulator is a tool that mimics some vision and hearing capability losses, allowing designers to load an image or sound and check the way different impairments and their severity would affect people's vision or hearing losses. Within the Exclusion Calculator, designers can discover the exclusion a product causes by selecting the necessary capability to use such product. The outcome is the overall exclusion (of the British population) or the exclusion based on each capability demand (Clarkson et al., 
2013). The majority of these virtual simulation tools are more widely disseminated in academia rather than in industry.

All tools shown in Table 1 have their advantages and their disadvantages: some are well integrated to the process during the conceptual phase, whilst others present effective results or visual and interactive interface. However, a combination of these three aspects was not found in a unique tool. Additionally, there is not a tool that directly connects designs under development with the exclusion it causes. This connection is proposed in this paper as a way to enable product developers to balance design requirements with design changes, and then gradually include small changes in their designs in favour of inclusivity.

Therefore, the scope of the present research was to understand how inclusive design tools could work in tandem on design processes, project requirements and product developers' interests.

\section{Methods}

In order to understand design practices, product developers participated in this research by being interviewed and observed and, as part of an iterative development process, evaluating different mock-ups of an inclusive design evaluation tool. This paper highlights two stages of the development process:

1) the initial (original) mock-up, in which the interactive tool was built into three dimensional modelling software (Google SketchUp) - Section 3;

2) the final version of the tool - the Inclusive Design Advisor - built in independent platform - Section 4.

\subsection{Sample selection and size}

Care was taken to ensure that research tools could be evaluated by product developers engaged in design processes in industrial contexts. Therefore, a purposive sample focusing on two specific groups - industrial designers and clients - formed this study. The designers were specialised in product design, research, and innovation for a broad range of industrial sectors and clients. The sample included packaging designers, product and interface designers of everyday small appliances, such as kettles, phones, remote controls and toasters. All these practitioners create the type of products that we find in retailers' catalogues or on the shelves of supermarkets. For example, Companies $\mathrm{G}$ and $\mathrm{H}$, in Table 2, are multinational telecommunication companies, with internal and external design teams working in new products. Companies B and J are specialised in producing packaging, while the others are specialised in producing small appliances. Hence, a better understanding of the design practice in such companies can elucidate how a great portion of everyday small appliances and packages are created.

In this research, clients were those people who commission the design from design agencies and who are responsible for representing the interests of the company that owns the final product, whether small or large companies. They take part in meetings to discuss or select design proposals; they can be product managers, owners of companies, marketing managers or manufacture engineers; or, in the case of large companies, all of them together. The companies and participants are listed in Table 2, where the names, whether companies, designers or clients, are replaced by titles like "Company A", "D1" and "C1" respectively to maintain their anonymity. All designers and clients are referred to by masculine pronouns, which was an option of the researcher, but does not mean that only male designers and clients participated in the study.

In a chain referral sampling mode, some companies indicated design agencies and some design consultancies indicated other consultancies. At the start, the researcher had only one contact person in each company, who contacted other employees and asked them about their availability and desire to participate in the study. A total of 38 designers and clients participated in the empirical study: 25 industrial designers and 13 clients. The sample of industrial designers was formed from six design agencies based in the United Kingdom and one multinational company; the clients were from the three large multinational companies and two small and medium enterprises.

The majority of the designers and clients had more than 10 years of working with product development, and seven of them (head of design teams) had more than 20 years of design experience. Table 2 details the number of participants and their respective positions, companies, and the way they participated in the study. Depending on their availability, the participants were interviewed or observed, but all of them gave feedback related to the tool presented to them. The final version of the tool was tested within live projects in two companies - C and G.

\subsection{Procedure}

The procedure was to ask the participants to talk about the design process as it occurs in their work routine. In most cases, they described a design process based on examples. After the interviews, the participants were asked to comment on a tool presented to them. As a result, their impressions, opinions and suggestions were gathered and used to further develop the tool.

The main topics covered in all interviews were: the design process; the techniques used to assess end-users' needs; the types of design tools used; what influences design decisions, and how requirements are prioritised and decisions are taken. They were audio recorded and transcribed afterwards. The interviews supported in-depth investigation of the design activity through opinions, knowledge, and experience of the participants; whereas the observations contextualised what was mentioned in the interviews and brought new insights to the research, as the behaviour of the participants. Zitkus et al. (2013a \& 2013b) detail the contribution made by the interviews, observations and demonstrations to the development of the tool.

The initial tool was developed based on past studies suggesting that CAD or three dimensional (3D) modelling software provide an effective environment to communicate with designers. (Hussain et al., 2016; Kaklanis et al., 2013; Macdonald and Loudon, 2007; Porter and Porter, 1999). Based on the feedback received (detailed in the next section) the tool was changed to one built in independent platform instead of 3D software. In this platform, multiple interfaces were presented to designers in an iterative process; however, the major changes were made in the initial tool, thus it is that initial tool which is presented in this paper (next section), as well as the final version (presented in section 4).

\section{The initial interactive evaluation tool}

An interactive tool built into Google SketchUp, which is a 3D modelling software program, was demonstrated to designers. It was built using simple codes in the Ruby programming language; however, the interactive settings were not fully implemented as it was in the development phase. Therefore, the tool was used for demonstration purposes only, simulating the actions taken by a designer who wants to assess the legibility of a design element. It demonstrated the factors that have to be considered to evaluate legibility. For example, among the steps taken were: 'setting the design material'; 'setting the colour'; 'setting the text style'; 'setting the luminosity of the environment'; 'setting the reading distance', 
Table 2

Table of participants and the methods used.

\begin{tabular}{|c|c|c|c|c|}
\hline Company & Participants & No. of participants & Demonstrations Interviews \& Observations & Test in live commercial product \\
\hline \multirow[t]{4}{*}{ Company A } & Product Design Managers & 2 & $\checkmark$ & \\
\hline & Senior Product Designers & 2 & $\checkmark$ & \\
\hline & Product Designer & 1 & $\checkmark$ & \\
\hline & Interface Designer & 1 & $\checkmark$ & \\
\hline \multirow[t]{7}{*}{ Company B } & Product Designer Manager & 1 & $\checkmark$ & \\
\hline & Packaging Designer Manager & 1 & $\checkmark$ & \\
\hline & Senior Product Designers & 2 & $\checkmark$ & \\
\hline & Product Designers & 2 & $\checkmark$ & \\
\hline & Senior Packaging Designers & 1 & $\checkmark$ & \\
\hline & & 1 & $\checkmark$ & \\
\hline & Graphic Designer & 1 & $\checkmark$ & \\
\hline \multirow[t]{2}{*}{ Company $\mathrm{C}$} & Product Designer Manager & 1 & $\checkmark$ & \\
\hline & Product Designer & 1 & $\checkmark$ & $\checkmark$ \\
\hline \multirow[t]{3}{*}{ Company D } & Senior Product Designer & 1 & $\checkmark$ & \\
\hline & Senior Product Designer & 1 & $\checkmark$ & \\
\hline & Senior Product Designer & 1 & $\checkmark$ & \\
\hline Company E & Product Designer Manager & 1 & $\checkmark$ & \\
\hline \multirow[t]{2}{*}{ Company $\mathrm{F}$} & Product Designer Manager & 1 & $\checkmark$ & \\
\hline & Senior Product Designer & 1 & $\checkmark$ & \\
\hline \multirow[t]{2}{*}{ Company G } & Web Designers & 2 & $\checkmark$ & \\
\hline & Product Manager & 1 & $\checkmark$ & $\checkmark$ \\
\hline \multirow[t]{6}{*}{ Company $\mathrm{H}$} & New Concept Manager & 1 & $\checkmark$ & \\
\hline & I\&D Senior Researcher & 1 & $\checkmark$ & \\
\hline & Usability Manager & 1 & $\checkmark$ & \\
\hline & Usability Consultant & 1 & $\checkmark$ & \\
\hline & Product Engineers & 2 & $\checkmark$ & \\
\hline & Product Manager & 1 & $\checkmark$ & \\
\hline Company I & Company's Founder \& Product Manager & 2 & $\checkmark$ & \\
\hline Company J & Product Manager & 2 & $\checkmark$ & \\
\hline Company k & Company's Founder \& Product Manager & 1 & $\checkmark$ & \\
\hline \multirow[t]{2}{*}{11 companies } & Designers & 25 & 38 & 2 \\
\hline & Clients & 13 & & \\
\hline
\end{tabular}

and other environmental and design elements that had to be set before evaluating the legibility of labels and texts in a 3D context.

The aim of the tool was to highlight the exclusion that designs under development can cause. As such designs were under development, product developers could be able to balance design requirements with design changes, and then, gradually include small alterations in their designs in favour of inclusivity.

Two examples were demonstrated to the participants, one that emulated the design of a simple medicine pack and another that emulated the design of a remote control. Both examples proposed an interactive way to check the legibility of the letters on the pack or on the remote control. Briefly, the demonstration of the remote control (illustrated in Figs. 3-5) followed the sequence below:

1. Designing a box (with colour and material), adding text (with font size and style) and setting the simulation scenario, such as ambient light, reading distance, etc.

2. Selecting Inclusive design in the Tools drop-down menu, and the visibility test.

3. An alert box opened that described the range of population excluded from reading the text. Also, it gave some advice regarding font size, style, and background/foreground colour contrast.

The reason for showing an alert box (such as the one in Fig. 5) was to understand whether designers would find the inclusivity information and the recommended action that followed useful changes to font size, style and background/foreground colour contrast - which aimed to guide designers towards re-creating more legible, or more inclusive features. The demonstrations stimulated debate among the participants, who talked about the pros and cons of the tool related to design practice. They were asked about the tool's interface, its functionality; the information and results provided.

\subsection{Results of the demonstrations}

The participants provided feedback on three main aspects of the tool: 1 ) the type of interface; 2 ) information supplied, and; 3 ) results that could make an inclusive design evaluation tool more adequate for design practices. Zitkus et al. (2013a,b) describes in more detail the comments of the designers and clients regarding the 3D tool, which, in summary, are the following aspects:

1. Interactive interfaces: the first issue was whether the participants believed that an interactive tool built into design software would be useful. The designers had a positive response to the concept. All product designers interviewed were keen about the idea of using 3D software to incorporate an inclusive design analysis, as they tend to design in 3D modelling tools. In other design domains, however, designers do not necessarily use 3D software. Thus, although 3D tools are preferred by product designers, other domains, such as packaging, graphic, interface designers and clients would prefer 2D software. However, all participants agreed that interactive tools similar to the one presented are preferable.

2. Information about inclusivity: a controversial aspect of the tool was its result related to the percentage of the British adult population excluded. According to some of the designers, exclusion information based on a percentage of the entire population may not affect the product's target market. For the clients, on the other hand, it may indicate opportunities in the 


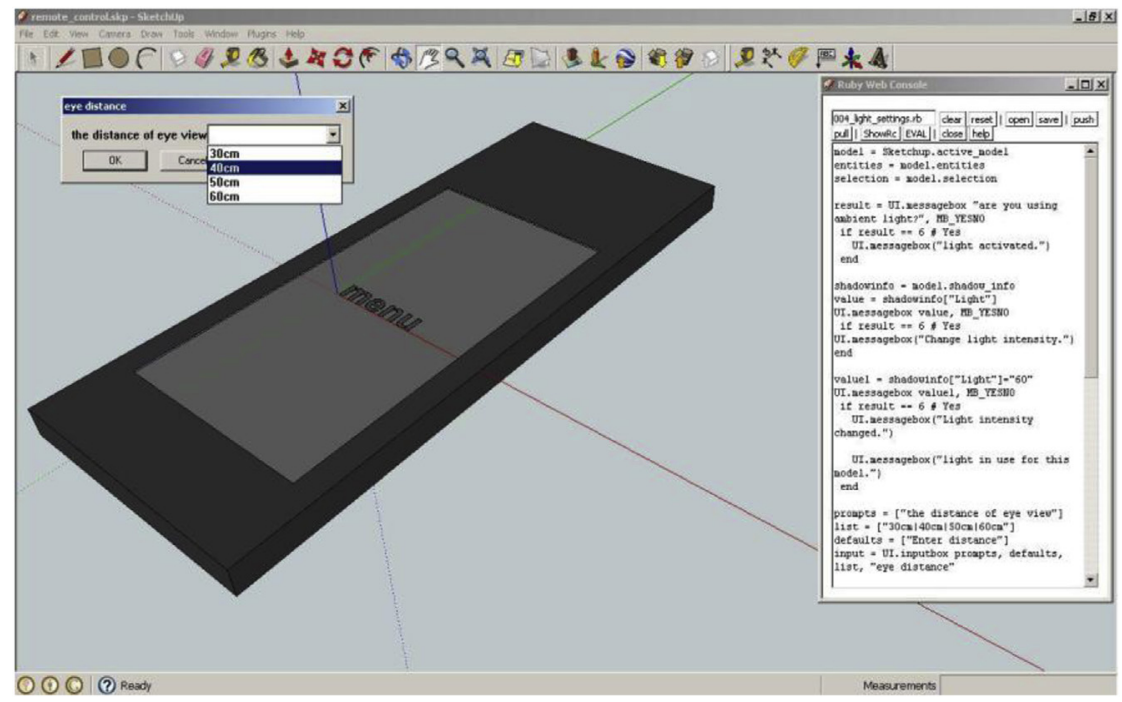

Fig. 3. Setting the reading distance among other design and environmental parameters.

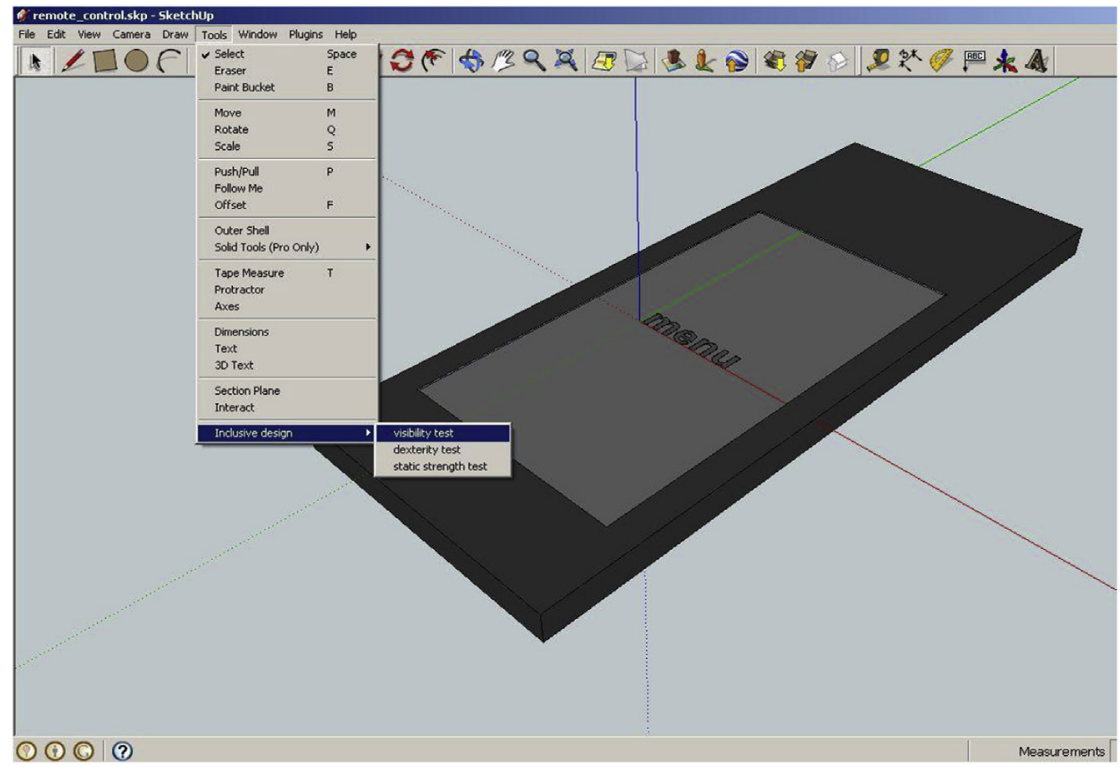

Fig. 4. Selecting the inclusive design test tool, in this case, visibility.

market. However, both groups suggested that the percentage of the population excluded could be divided into demographic groups, like age groups, social classes, etc. These groups are often associated with market requirements and could value the data.

3. Objective results: another aspect that required understanding was whether the evaluation of design features under development is an effective way to improve inclusivity in new designs. All designers mentioned they would like to receive more detailed information than was provided in the tool such as information directly related to the design they are creating; what is recommended to enhance inclusivity, and the best features for better inclusivity.

After considering the feedback received from participants regarding the initial tool, more developed interfaces of the tool led to changes in two main aspects:
1) the tool was built on an independent platform on the web Ruby On Rails application - which meant it was not restricted to product designers (like those built in CAD), but was available to be used by other design domains, as well as by clients.

2 ) it continued to evaluate the design under development and to estimate the exclusion of the British adult population. However, through the iterative development process, the details of the results were improved to satisfy designers: recommendations and parameters to improve inclusivity were added to the results.

A further developed tool with the last version of its interface is detailed in the next section.

\section{A further developed tool: the Inclusive Design Advisor}

As in the initial tool, the basic requirement of the Inclusive 


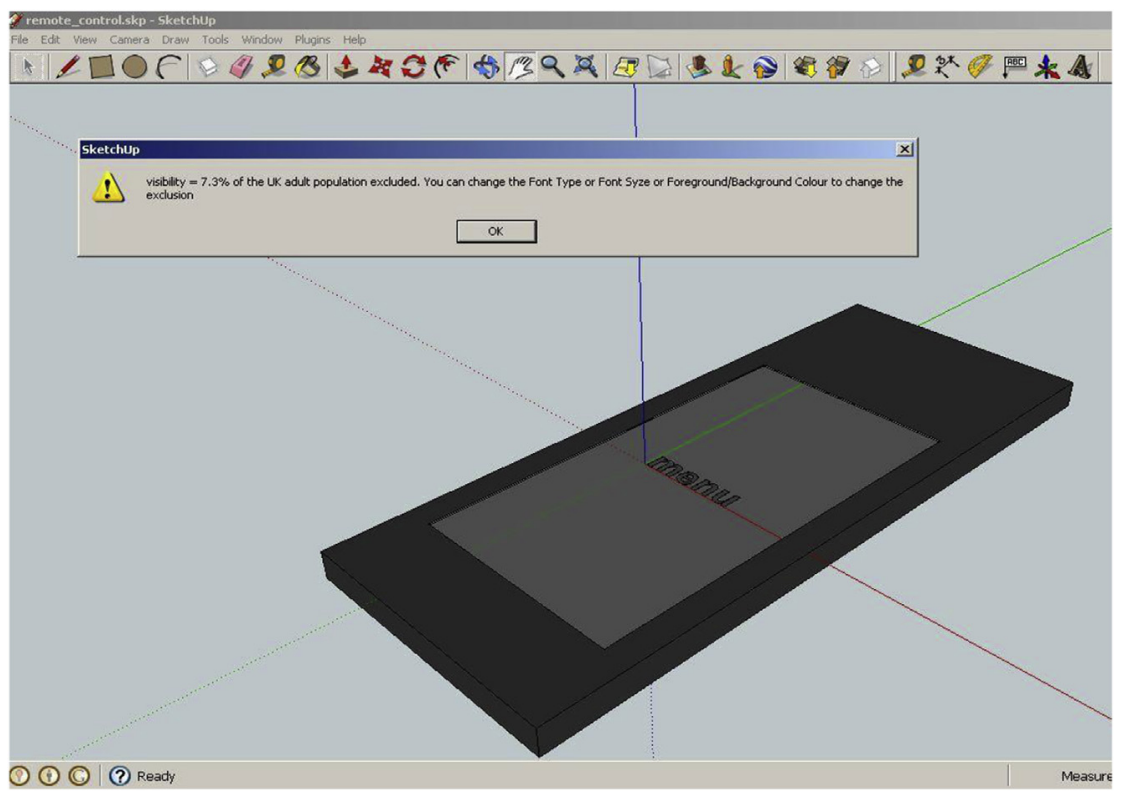

Fig. 5. Showing the inclusivity result of the visibility test-an exclusion of $7.3 \%$ of the UK adult population.

Design Advisor was to enable designers and clients to interactively audit the inclusivity of emerging designs.

Information about the characteristics of the design features of a design under development have to be entered in the system and feedback is given related to the inclusivity of these features.

For example, in a new design of a toaster, in order to evaluate the legibility of each design feature, it is mandatory to enter in the system the attributes of each element - i.e. to evaluate the legibility of a switch and its labels, it is mandatory to enter in to the Inclusive Design Advisor the background colour, the attributes of the switch such as size, colour, material's finishing, and also the attributes of the label, like text size, colour and style. Then the exclusion related to legibility issues is calculated. By changing any attribute, new feedback related to the exclusion is supplied. The information delivered by the tool is the estimation of the percentage of the British adult population excluded from comfortably seeing or handling the design, and the recommendations to enhance the design.

The key design requirements of the Inclusive Design Advisor were based on the outcomes from the exploratory study conducted since the initial tool was developed. They are highlighted below:

1. The interface of an inclusivity tool: an independent platform.

The Inclusive Design Advisor was built on an independent platform on the web. Although it is not built in a 3D modelling software, the interface is visual, with images and graphical information, as suggested in the literature as a preferred means to communicate with designers (Macdonald and Loudon, 2007; Porter and Porter, 1999), and confirmed in the interviews. Fig. 6 shows the starting page of the application.

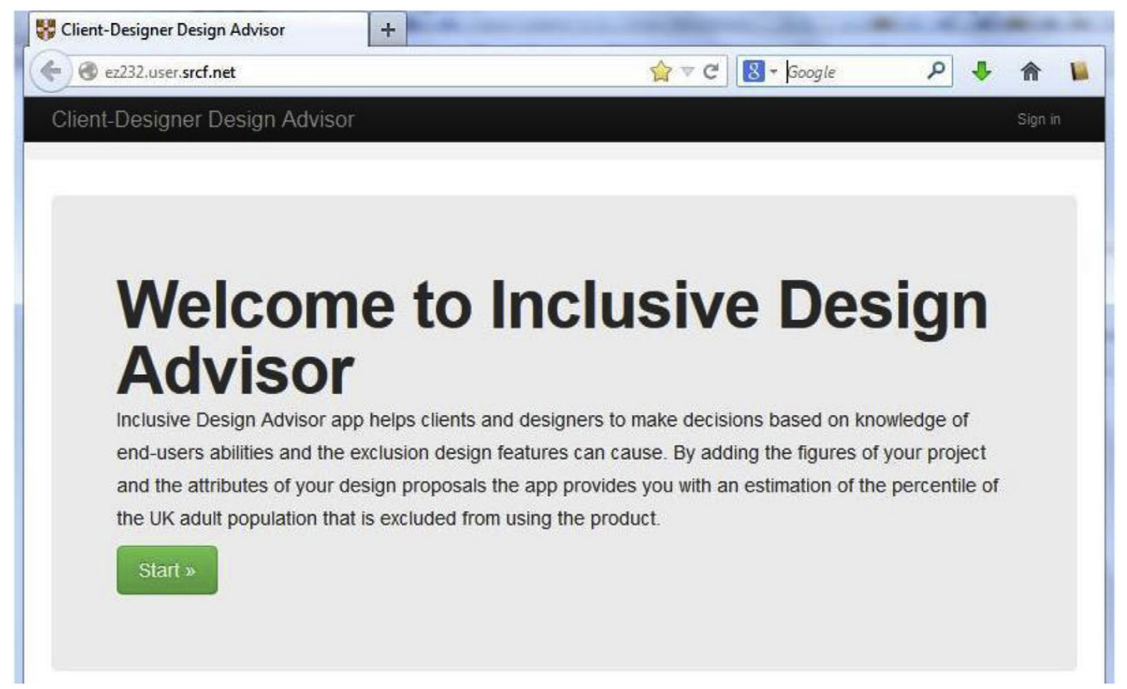

Fig. 6. The Inclusive Design Advisor starting page. 


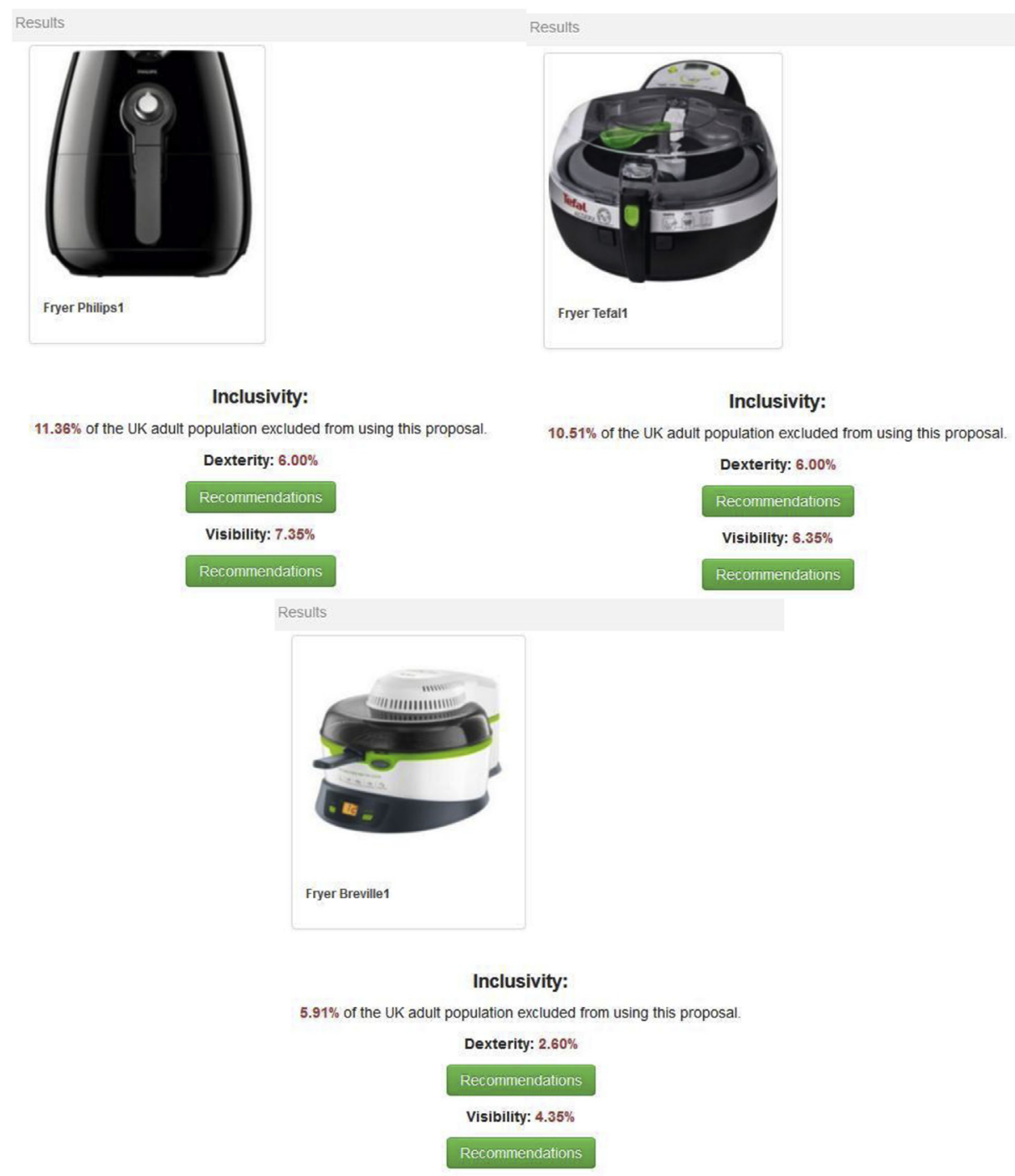

Fig. 7. The inclusivity information in the Inclusive Design Advisor: results of three healthy fryers audited.

2. The information about inclusivity: percentage of the UK adult population.

As suggested in the literature and reinforced in the interviews, the quantifiable data is mainly interesting for clients (Dong et al., 2003). As the concept was developed for use by designers and clients, the Inclusive Design Advisor informs users of the percentage of the British adult population excluded. However, it estimates the end-user exclusion related to dexterity and visual capabilities only. Problems related to legibility and dexterity affect a great portion of packaging designs and everyday small appliances, which could be minimised by small changes in the design. These small changes can greatly impact the accessibility and usability of new concepts. Other problems, such as those related to cognitive and other physical or sensorial capabilities are not identified neither are the exclusions estimated. Fig. 7 shows the exclusion results of products uploaded in the tool.

3. Objective results: inclusive design recommendations easily accessed
The tool is supplied with recommendation buttons for each exclusion value, whether related to vision or dexterity (green buttons in Fig. 7). Once the button is activated the screen that opens is a recommendation screen with design guidance as well as parameters for better inclusivity (shown in Fig. 8).

Each recommendation is related to a design feature uploaded and it is a link that takes the user (designer or client) to the attributes that could be improved. Therefore, the user can change them and check the difference it makes to the inclusivity of the feature.

\subsection{How to audit the inclusivity of designs}

In general, five steps must be taken to audit a design using the Inclusive Design Advisor. Fig. 9 illustrates these five steps: 1) start the application; 2) name a project; 3 ) load the design proposals (the renderings are for visual reference); 4) enter the design attributes of each features; 5) check the results (like those shown in Fig. 7). The attributes screens are detailed in the next sections (Fig. 10). In other words, the users upload renderings of concept designs under 


\section{Recommendations}

Dexterity: $6.00 \%$

timer (knob): $6.00 \%$

- Reduce the twisting force to less than $0.56 \mathrm{Nm}$

- Increase knob size for comfortable use (at least $29 \mathrm{~mm}$ - external diameter).

temperature (knob): $4.80 \%$

- Reduce the twisting force to less than $0.56 \mathrm{Nm}$

Fryer Philips (proposal): $1.80 \%$

- Change the product weight to less than $400 \mathrm{~g}$.

\section{Recommendations}

Visibility: $7.35 \%$

timer (label): $7.35 \%$

- Increase text size.

- Increase background-foreground colour contrast (background colour-text colour).

- $100 \%$ black in $100 \%$ white is the best foreground-background contrast.

temperature (label): $5.35 \%$

- Increase text size.

temperature (knob): $3.35 \%$

- Increase background-foreground colour contrast (background colour-knob colour).

- $100 \%$ black in $100 \%$ white is the best foreground-background contrast.

timer (knob): $3.35 \%$

- Increase background-foreground colour contrast (background colour-knob colour).

- $100 \%$ black in $100 \%$ white is the best foreground-background contrast.

Fig. 8. Two examples of the recommendations screens for dexterity and legibility.

development; complete the details about colour, shape, dimensions of each design feature, such as switches, buttons and labels, and run the tests. Next, they check the results to understand the exclusion that each feature could cause. By activating the recommendations buttons, they are able to understand what could be done to improve the feature in terms of inclusivity.

\subsection{The relationship between exclusion and design features}

In order to enable the system to calculate the exclusion results related to design features, some sources of information were used to create the algorithms that run the software. Firstly, the OPCS Surveys Of Disability In Great-Britain, Report 1 - The Prevalence Of Disability Among Adults (Martin et al., 1989), which relates the tasks individuals cannot perform to its implicit disability severity - called severity scores. Secondly, the Disability in Great Britain: Results from the 1996/1997 disability follow-up to the family resources survey (Grundy et al., 1999) which connects the severity scores to age groups and then to the percentages of the

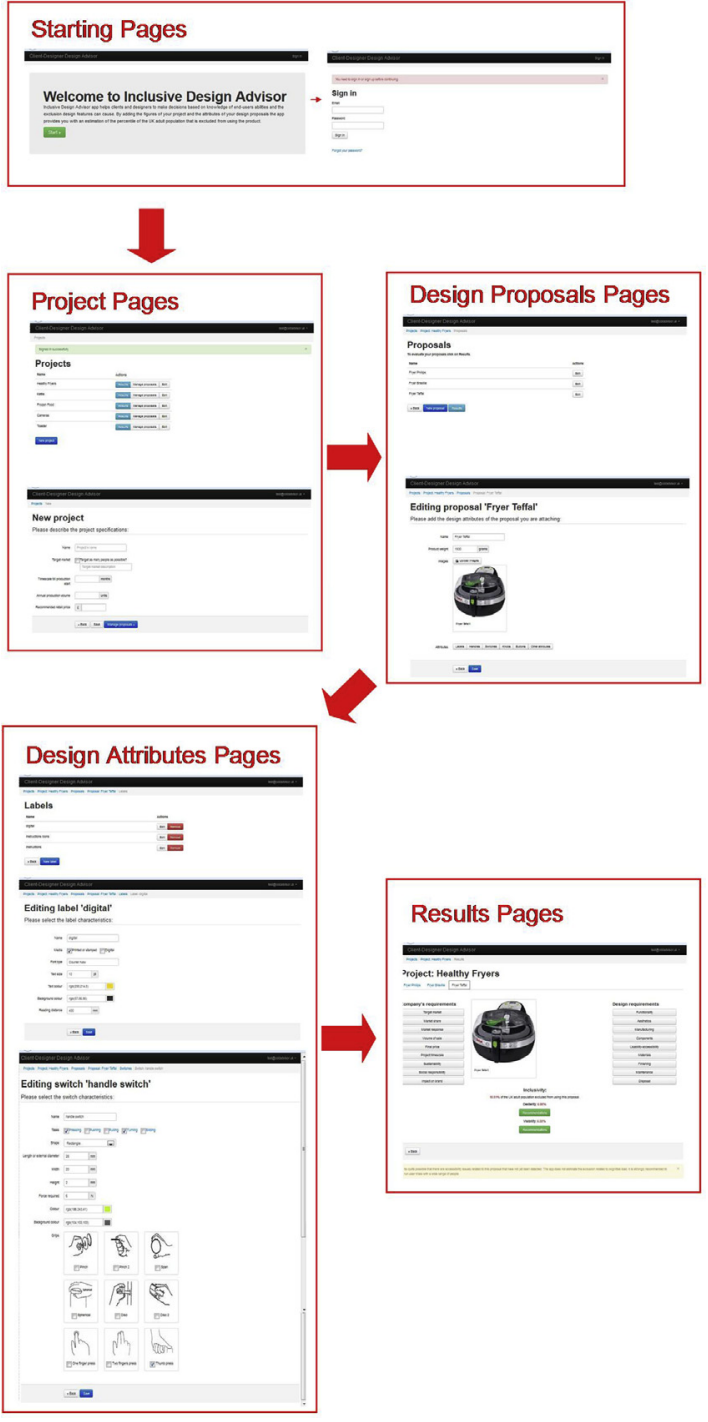

Fig. 9. The steps followed to audit a design.

UK adult population (Grundy et al., 1999 p. 35-54). Then, to fill the gaps between tasks and design attributes, the present research used the Older Adult Data (Smith et al., 2000) combined with a selection of past ergonomics studies conducted with older adults, as well as some of the web content accessibility guidelines (WCAG 2.0).

\subsubsection{Disability related to dexterity tasks and design attributes}

In the OPCS survey, all disability severity scores are related to tasks (as presented in Table 3 ) and consequently to design attributes involved in these tasks. For example, the dexterity task "cannot pick up and carry a $5 \mathrm{lb}$ bag of potatoes" is related to design attribute (weight of approximately $2 \mathrm{~kg}$ ) and a task (to pick up and carry); "cannot pick up and hold a mug of coffee" is also related to weight (approximately $400 \mathrm{~g}$ ) and a task (to pick up and hold). Weight is a design attribute that can exclude people from using a product. In other cases, the dexterity severity scores are related to the precision of the task, examples of which are "cannot turn or control knobs on a cooker" or "cannot pick up a 

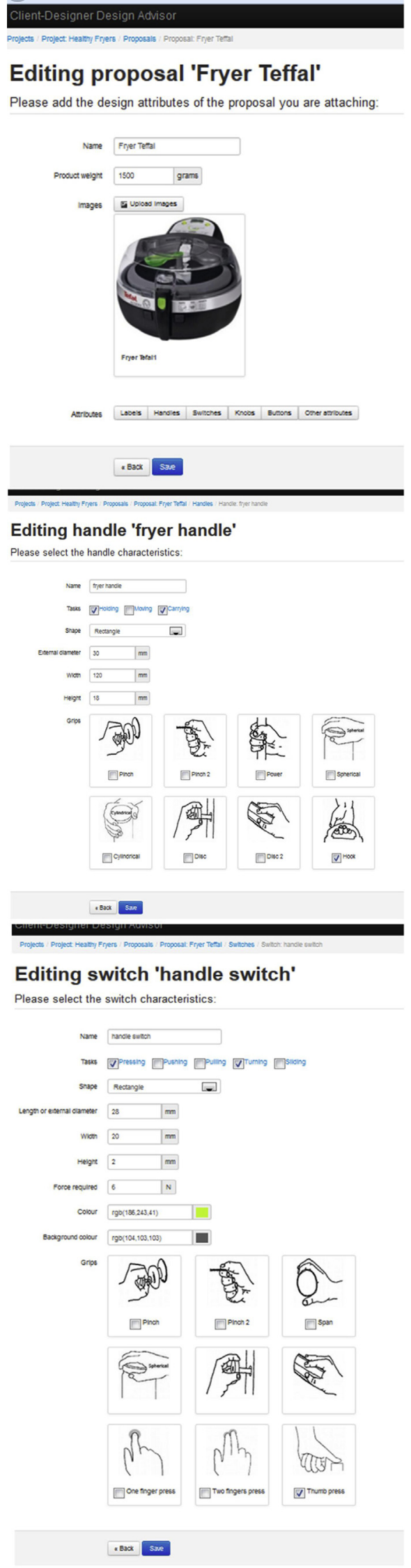

small object such as a safety pin". In these cases, the size of the design feature, the shape, the necessary strength and the grip type used to manipulate the feature can exclude people. Thus, the rules of the software considered weight, size, shape, force, type of tasks ${ }^{1}$ and grip types required to manipulate design features such as handles, buttons, switches or knobs.

Fig. 10 presents the Inclusive Design Advisor attributes, such as task, shape, dimensions, force, grip type; all used as data that rules the system, calculating the exclusion caused by the design and making recommendations to improve the features.

Also, the Inclusive Design Advisor rules are based on past ergonomic studies that related design features to capabilities of older adults. Some of the studies are those presented on the Older Adult Data: the handbook of measurements and capabilities of the older adult; data for design and safety (Smith et al., 2000). However, they were conducted with healthy older adults. Thus, other dexterity studies conducted with elderly people with reduced capabilities were also considered to complement the data. For example, the pinch strength presented in Smith et al.(2000) is too high to be used as an inclusive design guideline. As a result, the findings of Voelz and Hunt (1987) were used, which underline that women with arthritis apply 56\% of the force able-bodied women apply. This finding guided some of the force limit values used in the Inclusive Design Advisor. Some of the ergonomic studies used in the Inclusive Design Advisor to assess inclusivity of handles, buttons, switches and knobs are presented in Table 4.

\subsubsection{Disability related to vision tasks and design attributes}

Similarly to the dexterity scales, the vision disability severity scores are related to tasks and design attributes, as it is presented in Table 5. For instance, the tasks "has difficulty reading ordinary newspaper print", "cannot see well enough to read a large print book" and "cannot see well enough to read a newspaper headline" are related to design attributes - text size 12 pts, 16 pts and 18 pts respectively, as well as text colour in contrast to background colour. Therefore, the rules of the Inclusive Design Advisor considered the size of design features or the size of texts in products (i.e. products' labels), as well as the reading distance assumed during the use of the product. These design attributes are used as a parameter to calculate the exclusion related to the legibility of labels, buttons, switches and knobs.

Fig. 11 presents the Inclusive Design Advisor attributes, such as colour, size of texts (or size of features), reading distances and others; all used as part of the rules that calculates the exclusion and makes recommendations to improve the design.

Other sources used to formulate the algorithms of the vision rules were the W3C - WCAG2.0 Guidelines (www.w3.org/TR/ WCAG20/). These web guidelines are useful to relate size of texts to colour contrasts (Romen and Svanaes, 2012), which results in legibility of texts. In particular, two guidelines and their formulas were used in the tool, G17 and G18. G17 is to ensure that a contrast ratio of at least 7:1 exists between text and background behind the text and G18 is to ensure at least 4.5:1 contrast ratio between text and background. The smaller the text size, the greater the contrast should be. The larger the text and the contrast, the smaller is the exclusion.

The formula presented in W3C - WCAG2.0 that measures the relative luminance of the text was adapted to the Inclusive Design Advisor to calculate the contrast ratio (shown below).

The contrast ratio is then checked as to whether it is equal to or greater than 4.5 or 7 according to the size of the text in each case
Fig. 10. The design attributes and other aspects necessary to audit design features. From top to bottom: a product audited - a healthy fryer, its handle, and switch.

\footnotetext{
${ }^{1}$ all tasks were considered one-off tasks of short duration.
} 
Table 3

Dexterity severity score according to OPCS Surveys of Disability in Great Britain (Martin et al., 1989).

\begin{tabular}{|c|c|}
\hline Dexterity Tasks & Severity Score \\
\hline 1. Cannot pick up and hold a mug of coffee with either hand & 10.5 \\
\hline 2. Cannot turn or control knobs on a cooker with either hand & 9.5 \\
\hline 3. Cannot pick up or carry a pint of milk or squeeze the water from a sponge & 8.0 \\
\hline 4. Cannot pick up a small object such as safety pin with either hand & 7.0 \\
\hline 5. Has difficulty picking up and pouring from a full kettle or serving food from a pan using a spoon or ladle & 6.5 \\
\hline 6. Has difficulty unscrewing the lid of a coffee jar or using a pen or pencil & 5.5 \\
\hline 7. Cannot pick up and carry a 5lb bag of potatoes with either hand & 4.0 \\
\hline 8. Has difficulty wringing out light washing or using a pair of scissors & 3.0 \\
\hline 9. Can pick up and hold a mug of tea or coffee with one hand but not the other & 2.0 \\
\hline 10. Can turn a tap or control knob with one hand but not with the other/Can squeeze the water from a sponge with one hand but not the other & 1.5 \\
\hline 11. Can pick up a small object such as a safety pin with one hand but not with the other/Has difficulty tying a bow in laces or strings & 0.5 \\
\hline
\end{tabular}

(each label).

\subsubsection{Population exclusion caused by design attributes}

To make the linkage between design attributes and exclusion it was necessary to relate the disability severity groups to the portions of the population, which was a result of Grundy et al. (1999) work.

In Grundy et al. (1999 p. 35-54) the disability score (Tables 3 and 5) used on OPCS survey is weighted and related to severity category of disability, divided into groups from 1 to 10 . This severity category is associated with population age groups and then the percentage of the population. Table 6 presents the severity category

Table 4

Some of past ergonomic studies relating design features with older adult capabilities. The last column on right shows some of the data used in the software.

\begin{tabular}{|c|c|c|c|c|}
\hline Author & $\begin{array}{l}\text { Year of } \\
\text { publication }\end{array}$ & Sample & Methods & $\begin{array}{l}\text { Results used in the Inclusive Design Advisor for } \\
\text { knob, switch and button rules }\end{array}$ \\
\hline Smith et al. & 2000 & $\begin{array}{l}42 \text { healthy and able-bodied males } \\
\text { and females participants aged } 60 \\
-97 \text { years old. }\end{array}$ & $\begin{array}{l}\text { The results of these studies were used as design } \\
\text { guidelines in the Older Adult Data: the handbook } \\
\text { of measurements and capabilities of the older }\end{array}$ & $\begin{array}{l}\text { All the results related to force were too high to } \\
\text { be used as design guideline. The Voelz and Hunt } \\
\text { (1987 - below in the table) finding that women }\end{array}$ \\
\hline Smith et al. & 2000 & $\begin{array}{l}100 \text { males and } 100 \text { females } \\
\text { participants aged } 62-92 \text { years old. }\end{array}$ & $\begin{array}{l}\text { adult; data for design and safety (Smith et al., } \\
\text { 2000). However the methods are not clearly }\end{array}$ & $\begin{array}{l}\text { with arthritis apply } 56 \% \text { of the force able-bodied } \\
\text { women apply was used. }\end{array}$ \\
\hline Smith et al. & 2000 & $\begin{array}{l}556 \text { healthy participants divided } \\
\text { into } 6 \text { groups: } 55-59 \text { years old; } 60 \\
\text { to } 64 ; 65 \text { to } 69 ; 70 \text { to } 74 ; 75 \text { to } 79 \\
\text { and above } 80 \text { years old. }\end{array}$ & $\begin{array}{l}\text { mentioned, neither is the sample selection } \\
\text { detailed. }\end{array}$ & \\
\hline Smith et al. & 2000 & $\begin{array}{l}38 \text { participants ( } 15 \text { males and } 23 \\
\text { females) aged } 60-75 \text { years old } \\
\text { participants (not specified whether } \\
\text { healthy and able-bodied) }\end{array}$ & & $\begin{array}{l}\text { Round knob with } 28 \mathrm{~mm} \text { diameter: maximum } \\
\text { force } 0.56 \mathrm{~N} / \mathrm{m}\end{array}$ \\
\hline Rahman et al. & $\begin{array}{l}1997 \& \\
1998\end{array}$ & $\begin{array}{l}36 \text { elderly participants divided into } \\
\text { three groups: able-bodies, arthritis } \\
\text { and tremor groups . Each group } \\
\text { containing } 12 \text { individuals, male and } \\
\text { female participants over the age of } \\
50 \text {. Participants in the Arthritis } \\
\text { group had arthritis affecting their } \\
\text { hands or fingers, and those in the } \\
\text { Tremor group had hand tremor. The } \\
\text { focus on arthritis was due to it } \\
\text { being the most prevalent chronic } \\
\text { condition related to dexterity. } \\
\text { Participants with hand tremor were } \\
\text { chosen to determine whether they } \\
\text { could successfully activate push- } \\
\text { button or switches with low force. }\end{array}$ & $\begin{array}{l}\text { To categorize push-button switches in terms of } \\
\text { their force and travel properties, a } 3 \times 3 \text { force- } \\
\text { travel matrix was created in which both force } \\
\text { and travel were characterized as either low, } \\
\text { medium or high. These ranges were extended at } \\
\text { their lower ends under the assumption that } \\
\text { people with disabilities would prefer exerting } \\
\text { low force and low travel. This assumption was } \\
\text { supported in part by findings (Kanis, } 1993 \text { - } \\
\text { below) that the index finger push strengths of } \\
\text { people affected with arthritis were as low as } \\
2.3 \mathrm{~N} \text {. }\end{array}$ & $\begin{array}{l}\text { - Use low force }(0.3 \mathrm{~N}-0.5 \mathrm{~N}) \text { with medium or } \\
\text { high travel sliding switches (l.0 mm- } \\
8.0 \mathrm{~mm} \text { ). If for some reason a higher } \\
\text { activation force is required, the maximum } \\
\text { activation force should not exceed } 2.0 \mathrm{~N} \text { and, } \\
\text { in this case, the travel should be limited to } \\
0.8 \mathrm{~mm} \text {. These recommendations are } \\
\text { primarily for consumer products used in } \\
\text { entertainment electronics or home } \\
\text { appliances. } \\
\text { - Switches characterized by a combination of } \\
\text { low force and low travel falling below } 0.35 \mathrm{~N} \\
\text { and } 0.2 \text { mm (e.g. feather-touch switches), } \\
\text { respectively, are highly undesirable since } \\
\text { users may experience inadequate feedback } \\
\text { concerning the status of the control. }\end{array}$ \\
\hline Rose & 1991 & $\begin{array}{l}60 \text { subjects - } 30 \text { females and } 30 \\
\text { males, who were likely to be or } \\
\text { were keyboard users. They were } \\
\text { randomly selected from an office } \\
\text { population. }\end{array}$ & $\begin{array}{l}\text { Finger weights were recorded by an apparatus } \\
\text { consisting of a support for the four finger tips of } \\
\text { the dominant hand. One of these supports } \\
\text { consisted of a digital force gauge. }\end{array}$ & $\begin{array}{l}\text { For no wrist or arm support to avoid accidental } \\
\text { key actuation: } 1 \mathrm{~N} \text { force should be required to } \\
\text { activate the keys. }\end{array}$ \\
\hline Kanis & 1993 & $\begin{array}{l}68 \text { participants divided into } 34 \\
\text { able-bodies and } 34 \text { with arthritis or } \\
\text { muscular dystrophy }\end{array}$ & Pinch strength measurements & $\begin{array}{l}\text { Not measurable results, but design guidelines: } \\
\text { - The user should not be required to make two } \\
\text { manipulations at the same time (i.e., pushing } \\
\text { and turning a knob); } \\
\text { - Push buttons are preferable to rotating } \\
\text { knobs; } \\
\text { - Designers should anticipate that users will } \\
\text { manipulate controls in different ways, so } \\
\text { controls should offer larger target areas and } \\
\text { more clearance than might be expected for } \\
\text { typical use (i.e. some users might require two }\end{array}$ \\
\hline
\end{tabular}


Table 4 (continued)

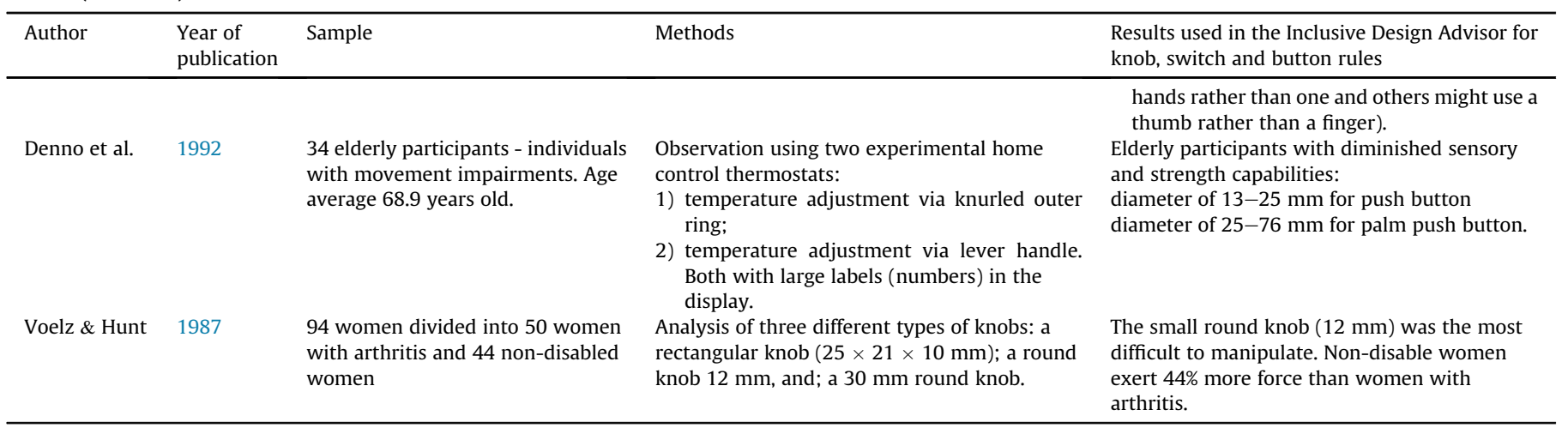

Table 5

Vision severity score according to OPCS Surveys of Disability in Great Britain (Martin et al., 1989).

\begin{tabular}{lc}
\hline Vision Tasks & Severity Score \\
\hline 1. Cannot tell by the light where the windows are & 12.0 \\
2. Cannot see the shapes of furniture in the room & 11.0 \\
3. Cannot see well enough to recognise a friend if close to his face & 10.0 \\
4. Cannot see well enough to recognise a friend who is an arm's length away & 8.0 \\
5. Cannot see well enough to read a newspaper headline & 5.5 \\
6. Cannot see well enough to read a large print book & 5.0 \\
7. Cannot see well enough to recognise a friend across a room & 4.5 \\
8. Cannot see well enough to recognise a friend across a road & 1.5 \\
9. Has difficulty reading ordinary newspaper print & 0.5 \\
\hline
\end{tabular}

\section{Client-Designer Design Advisor}

\section{Editing button 'on/off'}

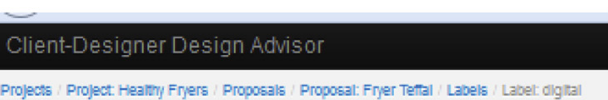

\section{Editing label 'digital'}

Please select the label characteristics:

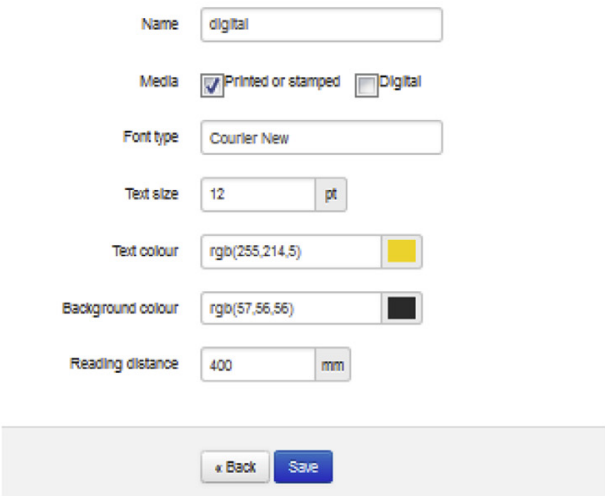

Please select the button characteristics:

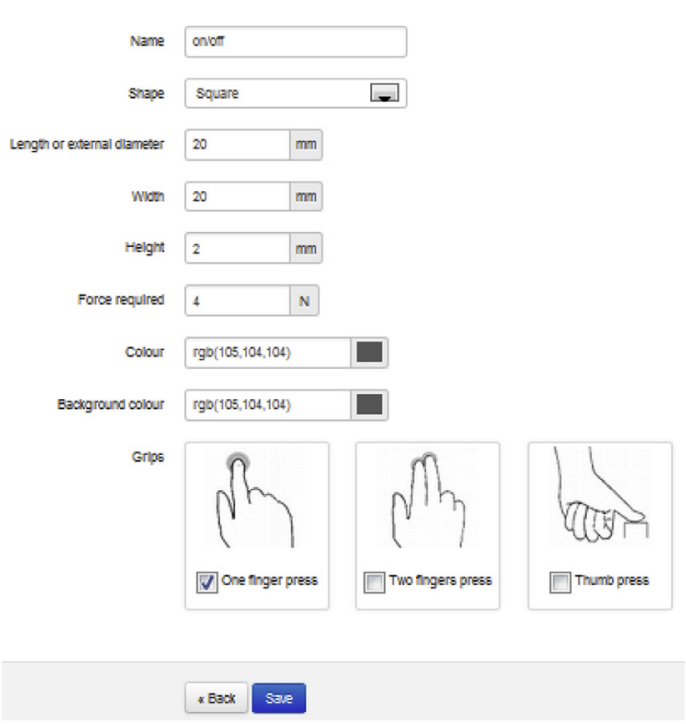

Fig. 11. The design attributes and other aspects necessary to audit the legibility of design features. On the left, a label and on the right a button of a product audited.

of disability, while Fig. 12 illustrates the way the severity categories are associated with age groups and the percentage of the population.

The Exclusion Calculator, a tool mentioned in the introduction, uses the same principle - it relates the OPCS survey with Grundy et al. work. However, it does not relate the exclusion to design attributes directly. Thus, although the Inclusive Design Advisor follows the same method to calculate the exclusion, it presents the exclusion in relation to design attributes; therefore, it makes recommendations that improve the design directly. 
Equation 4.1

The relative luminance equation to measure the text luminance and the background luminance (used in W3C - WCAG2.0)

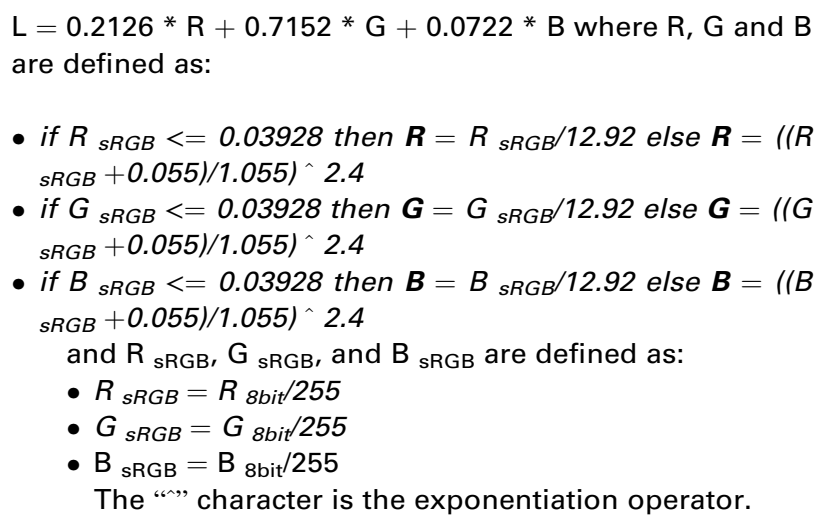

\section{Equation 4.2}

The relative luminance of text and background is then used to calculate the contrast ratio (used in W3C - WCAG2.0)

$$
(\mathrm{L} 1+0.05) /(\mathrm{L} 2+0.05)
$$

L2 is the relative luminance of the darker of the foreground or background colour.

$\mathrm{L} 1$ is the relative luminance of the lighter of the foreground or background colour;

Contrast ratios can range from 1 to 21 (commonly written $1: 1$ to $21: 1$ )

\section{Table 6}

Disability severity score related to severity category groups 1 to 10 according to Grundy et al. (1999).

\begin{tabular}{ll}
\hline Severity category & Weighted disability score \\
\hline 10 (most severe) & $19-21.40$ \\
9 & $17-18.95$ \\
8 & $15-16.95$ \\
7 & $13-14.95$ \\
6 & $11-12.95$ \\
5 & $9-10.95$ \\
4 & $7-8.95$ \\
3 & $5-6.95$ \\
2 & $3-4.95$ \\
1 (least severe) & $0.5-2.95$ \\
\hline
\end{tabular}

While developing the Inclusive Design Advisor, it was noted that there is a low number of studies that relates design features to older or disabled adults' capabilities. Also, in some cases, the study does not refer to sample and methodology clearly. For example, the Older Adult Data handbook (Smith et al., 2000) is not clear in terms of methodology and sample selection. Some of the design guidelines presented in the handbook suggest high forces even for young able-bodied women. Therefore, the rules and recommendations in the tool were generated from a combination of ergonomic studies (like those presented in Table 4). This illustrates a limitation, in that it is a combination of studies that form the database of the tool, and the linkage between them is not always precise. However, it serves as an initial step to formulate rules that could result in design

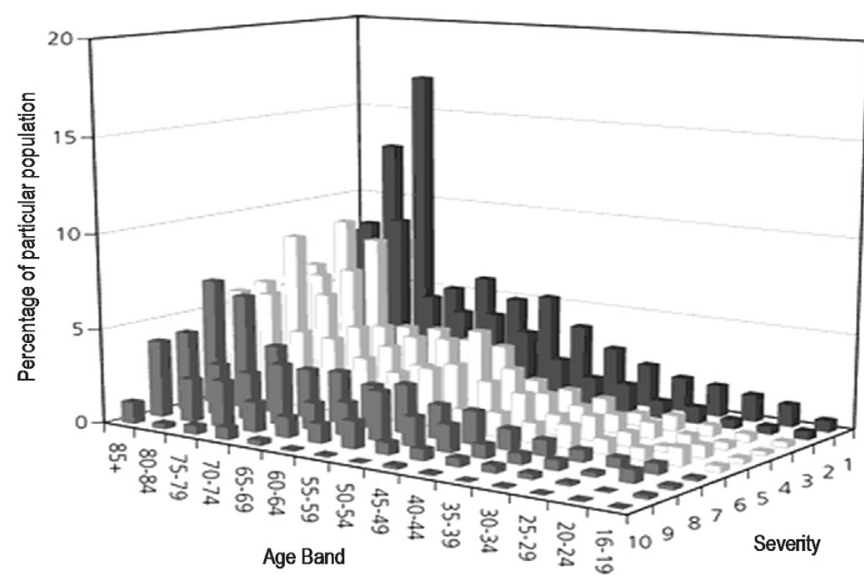

Fig. 12. Disability severity group by age band and percentage of the UK adult population according to Grundy (authors: Keates and Clarkson, 2003).

guidance for better and inclusive products.

\section{The tests using the Inclusive Design Advisor in live projects}

To test the Inclusive Design Advisor within live projects, oneweek access to the tool was given to the participants. Among the eleven companies presented in Table 2 that participated in the interviews and demonstrations, only two agreed to use the tool in live projects. A small device or packaging design under development was agreed and access to the tool was given to each participant. They were asked to take note of anything they found important while using the tool, including the reasons for accepting (or not) the design recommendations during the evaluations.

The tool was used by a product designer in one company, and a product manager (client) in the other. Table 7 details the two participants and the development stage of the new designs were while they were evaluated in the test.

The Inclusive Design Advisor was developed with features that register the user selections; thus, the actions taken were recorded in the system. Additionally, each participant was debriefed in the last day using the tool, when they explained the reasons for the design decisions taken. The data recorded in the system were useful to understand the way the participants used the tool and how many of the recommendations were implemented in the proposal. These data enabled a comparison of what was originally uploaded and what they ended up designing, contrasting the changes and the decisions made during the process. The results of the assessment clarified the usefulness of the concept behind the tool, which is the provision of inclusivity information directly related to the design under development. Thus, the tests were used to theoretically validate the concept.

\subsection{The first test: a dental bottle}

The designer - D16 - used the tool remotely (without any help) and after a week, he clarified the design decisions taken. He explained the project - a big bottle for dental hygiene - and the brief received from the client, stressing the design constraints present in it. The brief was: "a more modern look bottle", with the following features:

- volume: $2 \mathrm{~L}$;

- keep the existing cap, size and thread;

- the labelling is provided by the client and Company $C$ should not change it. It is associated with the corporate look and branding. 
Table 7

Participants and stage of the project when they tested the Inclusive Design Advisor.

\begin{tabular}{lll}
\hline Company & Participants & Stage of the project \\
\hline Company C & Product Designer - D16 & During the conceptual phase \\
Company G & Product Manager - C1 & After conceptual phase - detailing phase \\
\hline
\end{tabular}

The design proposal was uploaded in the tool with all the details about its attributes. Fig. 13 shows the inclusivity results. According to the automatic records of the Inclusive Design Advisor, D16 uploaded the design attributes, checked the results and the recommendations and changed some attributes to reduce the exclusion. However, he temporarily changed those attributes related to the brand identity and the lid manufacturing. The only design attribute that he changed and maintained changed was the handle, which improved the handle exclusion but not the overall dexterity exclusion as the force needed to turn the lid was the major dexterity issue (the one which excluded more people).

A week after being given access to the tool, D16 explained that in this project the changes in the design were very restricted. The brief restricted changes to the lid and graphic communication, both of which could improve inclusivity. He mentioned that the recommendations for better legibility did not work in that case as everything on the label had to consider the brand corporate identity, and thus be approved by the client. Within the design proposal uploaded in the Inclusive Design Advisor, they could adjust the handle of the bottle only.

\subsection{The second test: an assistive technology}

This test was conducted in a large multinational company Company $\mathrm{G}$ - with a product manager (C1) who is the person who represents the company's interests when commissioning the design from a design agency. He used the tool and evaluated a project in two days. He uploaded a product to be used by children with cerebral palsy. The exclusion results regarding dexterity and

\section{Inclusivity:}

$9.49 \%$ of the UK adult population excluded from using this proposal.

\section{Dexterity: $4.80 \%$}

Recommenditions

Visibility: $6.35 \%$

Recommendations

Fig. 13. The Inclusive Design Advisor results related to the design of a new dental hygiene bottle.

\section{Inclusivity:}

$9.66 \%$ of the UK adult population excluded from using this proposal.

\section{Dexterity: $6.00 \%$}

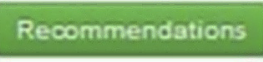

Visibility: $5.35 \%$

Recommendations

Fig. 14. The Inclusive Design Advisor results related to the assistive technology uploaded. legibility are shown in Fig. 14.

After entering the design attributes, including the force required to press the switches, $\mathrm{C} 1$ mentioned that if he had known the recommendations early in the process, he would have changed the size of the switches already. Instead of putting both on the same side of the product - the left - they could have placed one switch on each side.

"I would definitely change the size (from $9.4 \mathrm{~mm}$ to $13 \mathrm{~mm}$ ). The size would be bigger and I would increase the labels of the switches also. So, I do not have enough space, but I would have to put one switch here [on the right side of the product] and another switch there [on the left side of the product]. Keeping the same size [of the product], but with bigger switches on each side." (23:10 - C1)

The product manager - $\mathrm{C} 1$ - accepted most of the changes recommended by the Inclusive Design Advisor. He changed the switch pressing force, size of buttons, (even requiring changes on the button position) and size of labels. He took note of the recommendations and re-accessed the tool on other occasions - after the test - something recorded by the system, which indicates his intention to take the implementation forward.

The fact that the client accepted most of the changes does not mean that he did not consider other design requirements and design constraints. In fact, he explained the reason for not taking forward the change in colour contrast. According to him a colourful product is a design priority and thus the colour of the product would remain as it was.

\section{The final designs related to the information provided by the tool}

In the first test the designer - D16 - was not able to change most of the design attributes, as the majority of the changes highlighted by the tool demanded manufacture adjustments and brand identity modifications, which required the clients' approval. However, more important is the fact that one design attribute was changed, which was a design decision in favour of inclusivity. The size of the handle was changed due the specific information about inclusivity received. The system registered that other design attributes were also checked and temporarily changed to see the impact on the population excluded. The use of the tool in this test highlighted the effectiveness of supplying specific information about inclusivity.

In contrast to D16, in the second test, the product manager - C1 did not refer to consulting the designers before saying that he would change the design attributes. In fact, $\mathrm{C} 1$ accepted changes on force required, size of buttons (even requiring changes on the button position) and size of labels. The client's power suggests that the information provided by the Inclusive Design Advisor, such as the exclusion results and design recommendations, should not be exclusively supplied to designers. According to this test, it was effective to supply this information to clients also, which confirms previous studies that describe the power that clients exert on design decisions (Cornish et al., 2015; McDonnell and Lloyd, 2009; Le Dantec and Yi-Luen Do, 2009; Goldschmidt and Eshel, 2009; Oak, 2009). Hence, the provision of quantifiable inclusivity 
information directly related to the design under evaluation - as the results provided by the Inclusive Design Advisor - is a way to effectively influence project developers.

However, a number of limitations require future research to improve the tool. One is related to the shortage of studies that link design features with vision and dexterity capabilities of older adults and people with disabilities, which is the type of data that forms the database of the tool. Therefore, the tool could only audit small appliances or packages that had design features covered by the rules running the software. Even though it is important to emphasise that the tool indicates changes to enhance the inclusivity of the design, they are an initial and quick evaluation, feasible for design proposals during the conceptual phase. The variation between situations, such as the way end-users would understand and use a new design is immense, and difficult to predict in order to be covered by the rules of a system. Thus, ideally, user-trials with mock-ups of the proposals is recommended as part of the design process. There is a statement recommending user-trials in the 'result screen' below the recommendation button in the tool. The next step, however, is to build a more robust database based on more consistent research that links design features and design attributes to disability/reduced capabilities and its exclusion. Thus, further research with the purpose of generating inclusivity information and guidelines should be conducted. To some extent it has been conducted (Waller et al., 2016; Goodman-Deane et al., 2016) and in turn will serve to help develop a more precise tool.

Other limitations are related to the results given; the exclusion is based on the British population only. The percentage of the population affected by certain dexterity problems or vision impairment possibly varies from one country to another. This variation could be studied in order to propose more comprehensive results.

A limitation of the study presented was the fact that in industrial contexts commercial constraints, like confidentiality issues, made access to the projects under development difficult, which resulted in only two live projects being tested. However, the advantage of following live projects and design under development is that the results show the projects' constraints. For example, the designer and the client involved in the tests knew the reasons behind their design decisions and the trade-offs that enabled or hindered them from improving the inclusivity. Therefore, future research could assess more live projects to test future versions of the tool.

\section{Conclusions}

This paper presented an alternative tool, named Inclusive Design Advisor, developed to provide information about inclusivity that is directly related to design under development. The tool enables designers and clients to audit new designs of small devices or packaging design, assessing the overall population exclusion caused by dexterity and vision issues. In the tool, the exclusion is related to each design feature, followed by objective recommendations directly related to the design features and design attributes under evaluation. These results enable product developers to make design decisions in favour of inclusive designs. The iterative developing process used to develop the tool supported a better understanding of interfaces, information and results that could work in tandem on design processes, project requirements and product developers' interests.

The main differences between the tools currently available to evaluate inclusive design and the tool presented here are:

1) designs under development can be assessed and modifications suggested to enhance the inclusivity of them;
2) the interactive interface is accessible to clients and designers, while the information provided is useful for both designers and clients. For instance, the overall exclusion of the design can be related to the market to support clients to make design decisions; whereas the exclusion divided into design attributes and their specific recommendations can support designers to change design proposals. Thus, the tool can potentially persuade clients and designers to take inclusive design decisions.

The tool was tested within two live commercial projects, which had inclusive design changes implemented. Although there are a number of improvements to make the tool more robust and comprehensive, the tests indicated that specific information related to the design and the exclusion of each design feature is a way to influence clients and designers to develop more inclusive designs.

\section{Acknowledgements}

We would like to thank the Engineering and Physical Sciences Research Council (grant number 972367) and the India-UK Advanced Technology Centre (IU-ATC) for supporting the project of which this paper is part. Also, we are grateful to the comments, suggestions and criticism made by the reviewers, which helped to structure the paper, making it more intelligible. We would like to thank Ruth Ekblom for proofreading this paper.

\section{References}

Brajnik, G., Yesilada, Y., Harper, S., 2012. Is accessibility conformance an elusive property? A study of validity and reliability of WCAG 2.0. ACM Trans. Acc. Comput. 4 (2).

Burns, C.M., Vicente, K.J., Christoffersen, K., Pawlak, W.S., 1997. Towards viable, useful and usable human factors design guidance. Appl. Ergon. 28 (5-6), $311-322$.

Cardoso, C., Clarkson, J., 2007. User simulation in product evaluation. In: Coleman, R., Clarkson, J., Dong, H., Cassim, J. (Eds.), Design for Inclusivity - A Practical Guide to Accessible, Innovative and User-Centred Design. Gower, Aldershot.

Cassim, J., Dong, H., 2015. Interdisciplinary engagement with inclusive design. The Challenge Workshops model. Appl. Ergon. 46, 292-296.

Clarkson, P.J., Cardoso, C., Hosking, I., 2007. Product evaluation: practical approaches. In: Coleman, R., Clarkson, J., Dong, H., Cassim, J. (Eds.), Design for Inclusivity - a Practical Guide to Accessible, Innovative and User-centred Design. Gower, Aldershot.

Clarkson, P.J., Waller, S., Cardoso, C., 2013. Approaches to estimating user exclusion. Appl. Ergon. http://dx.doi.org/10.1016/j.apergo.2013.03.001.

Cornish, K., Goodman-Deane, J., Ruggeri, K., Clarkson, P.J., 2015. Visual accessibility in graphic design: a client designer communication failure. Des. Stud. 40, 176-195.

Denno, S., Metz, S., Isle, B., \& Li, W. (1992). Small Rotary Controls: Limitations for People with Arthritis. Paper presented at the Human Factors and Ergonomics Society Annual Meeting.

Dong, H., Keates, S., \& Clarkson, P. J. (2003). Designers and Manufacturers' Perspectives on Inclusive/Universal Design. Paper presented at the ICED - International Conference on Engineering Design 2003.

Eisma, R., Dickinson, A. Goodman, J., Syme, A., Tiwari, L, Newell, A.F, 2004. Early user involvement in the development of information technology-related products for older people. Univers. Access Inform. Soc. 3 (2), 131-140.

Eurostat, 2015. Disability Statistics - Prevalence and Demographics - Based on Prevalence of Disability (European Union Labour Force Survey - EU-LFS) and Prevalence of Disability (European Health and Social Integration Survey EHSIS). http://ec.europa.eu/eurostat/statistics-explained/index.php/Disability_ statistics - prevalence and demographics, accessed on 04/10/2016.

Goldschmidt, G., Eshel, D., 2009. Behind the scenes of the design theatre: actors, roles and the dynamics of communication. In: McDonnell, L.P.J. (Ed.), About: Designing - Analysing Design Meetings. Taylor and Francis Group, pp. 321-338.

Goodman, J., Dong, H., Langdon, P.M., Clarkson, P.J., 2006a. Factors involved in industry's response to inclusive design. In: Clarkson, P.J., Langdon, P.M., Robinson, P. (Eds.), Designing Accessible Technology. Springer-Verlag Ltd, London, pp. 31-41.

Goodman, J., Dong, H., Langdon, P.M., Clarkson, P.J., 2006b. Increasing the uptake of inclusive design in industry. Gerontechnology 5 (3), 140-149.

Goodman-Deane, J., Langdon, P., Clarkson, J., 2010. Key influences on the usercentred design process. J. Eng. Des. 21 (2-3), 345-373.

Goodman-Deane, J., Ward, J., Hosking, I., Clarkson, P.J., 2014. A comparison of methods currently used in inclusive design. Appl. Ergon. 45, 886-894. 
Goodman-Deane, J., Waller, S., Latham, K., Price, H., Tenneti, R., Clarkson, P.J., 2016. Differences in vision performance in different scenarios and implications for design. App. Ergon. 55, 149-155.

Grundy, E., Ahlburg, D., Ali, M., Breeze, E., Slogget, A., 1999. Disability in Great Britain: Results from the 1996/97 Disability Follow-up to the Family Resource. Department of Social Security, Leeds.

Happee, R., Wismans, J., 2009. Impact simulation and biomechanical human body models. In: Duffy, V.G. (Ed.), Handbook of Digital Human Modelling. Taylor and Francis, Boca Raton.

He, W., Larsen, L.J., 2014. U.S. Census Bureau, American Community Survey Reports, ACS-29, Older Americans with a Disability: 2008-2012. U.S. Government Printing Office, Washington, DC.

Henderson, K., 1999. On Line and on Paper Visual Representations, Visual Culture, and Computer Graphics in Design Engineering. MIT Press, Cambridge, Mass.

Hitchcock, D., \& Taylor, A. (2003). Simulation for Inclusion - true user centred design? In Include 2003. Vol. Conference Proceedings, 2003. London.

Hussain, A., Case, K., Marshall, R., Summerskill, S., 2016. Joint mobility and inclusive design challenges. Int. J. Indus. Ergon. 53, 67-79.

Johnson, D., Clarkson, J., Huppert, F., 2010. Capability measurement for inclusive design. J. Eng. Des. 21 (2-3), 275-288.

Kaklanis, N., Moschonas, P., Moustakas, K., Tzovaras, D., 2013. Virtual user models for the elderly and disabled for automatic simulated accessibility and ergonomic evaluation of designs. Univers. Access Inf. Soc. 12 (4), 403-425.

Kanis, H., 1993. Operation of controls on consumer products by physically impaired users. Hum. Factors J. Hum. Factors Ergon. Soc. 35 (June), 305-328.

Karlsson, M., 2013. Elderly users and new technology: the case of care homes and other contexts. In: Hujala, A., Rissanen, S., Vihma, S. (Eds.), Design Wellbeing in Elderly Care Homes. Crossover.

Keates, S., Clarkson, J., 2003. Countering Design Exclusion: An Introduction to Inclusive Design. Springer, London.

Le Dantec, C.A., Yi-Luen Do, E., 2009. The mechanisms of value transfer in design meetings. Des. Stud. 30 (2), 119-137.

Macdonald, A.S., Loudon, D., 2007. Designing data to be inclusive: enabling crossdisciplinary and participative processes. Univers. Access Hum. Comput. Interact. Coping Divers. 4554, 217-223.

Macdonald, A.S., Loudon, D., Rowe, P.J., Samuel, D., Hood, V., Nicol, A.C., 2007. Towards a design tool for visualizing the functional demand placed on older adults by everyday living tasks. Univers. Access Inf. Soc. 6 (2), 137-144.

Marshall, R., Cook, S., Mitchell, V., Summerskill, S., Haines, V., Maguire, M., Sims, R., Gyi, D., Case, K., 2015. Design and evaluation: end users, user datasets and personas. Appl. Ergon. 46, 311-317.

Martin, J., Meltzer, H., Elliot, D., 1989. OPCS surveys of disability in Great-Britain, Report 1-the prevalence of disability among adults - Williams, S. J. (Ed). Sociol. Health \& Illn. 11 (2), 187-189.

McDonnell, J., Lloyd, P., 2009. About: Designing - Analysing Design Meetings. Taylor and Francis Group.

Meyer-Hentschel, G., 2007. Design goes Universal. Thexis - Fachzeitschrift für Marketing 24, 28-32.

Moore, P., 1985. Disguised. Word Books, Waco, Texas.

Newell, A.F., Carmichael, A., Morgan, M., Dickinson, A., 2006. The use of theatre in requirements gathering and usability studies. Interact. Comput. 18 (5), 996-1011.

Nicolle, C., Abascal, J.G.E., 2001. Inclusive Guidelines for Human Computer Interaction. Taylor and Francis, London.

Norman, D.A., 2013. The Design of Everyday Things. Basic Books, New York.

Oak, A., 2009. Performing architecture: talking 'architect' and 'client' into being. CoDesign 5 (1), 51-63.

ONS, 2012. Population Ageing in the United Kingdom, its Constituent Countries and the European Union Report. Office for National Statistics.

ONS, 2014. Healthy Life Expectancy at Birth for Upper Tier Local Authorities: England, 2010-2012. Office for National Statistics.

Persad, U., Langdon, P., Clarkson, J., 2007. Characterising user capabilities to support inclusive design evaluation. Univers. Access Inf. Soc. 6 (2), 119-135.

Porter, C.S., Porter, J.M., 1999. Designing for usability: input of ergonomics information at an appropriate point and appropriate form in the design process. In: Green, W.S., Jordan, P.W. (Eds.), Human Factors in Product Design : Current Practice and Future Trends. Taylor \& Francis, London, pp. 15-25.

Rahman, M., Sprigle, S., 1997. Physical accessibility guidelines of consumer product controls. Assist. Technol. 9 (1), 3-14.

Rahman, M.M., Sprigle, S., Sharit, J., 1998. Guidelines for force-travel combinations of push button switches for older populations. Appl. Ergon. 29 (2), 93-100.

Rømen, D., Svanæs, D., 2012. Validating WCAG versions 1.0 and 2.0 through usability testing with disabled users. Univers. Access Inf. Soc. 11 (4), 375-385.

Rode, J.A., Toye, E.F., Blackwell, A.F., 2004. The fuzzy felt ethnography-understanding the programming patterns of domestic appliances. Personal Ubiquitous Comput. 8 (3-4), 161-176.

Rose, M.J., 1991. Keyboard operating posture and actuation force: implications for muscle over-use. Appl. Ergon. 22 (3), 198-203.

Sanford, J.A., Story, M.F., Ringholz, D., 1998. Consumer participation to inform universal design. Technol. Disabil. 9 (3), 149-162.

Selwyn, N., 2004. The information aged: a qualitative study of older adults' use of information and communications technology. J. Aging Stud. 18, 369-384.

Smith, S., Norris, B., Peebles, L., 2000. Older Adult Data: the Handbook of Measurements and Capabilities of the Older Adult, Data for Design and Safety. Institute for Occupational, Ergonomics: Consumer Safety Unit. Department of Trade an Industry. University of Nottingham, Great Britain.

Tenneti, R., Johnson, D., Goldenberg, L., Parker, R.A., Huppert, F.A., 2012. Towards a capabilities database to inform inclusive design: experimental investigation of effective survey-based predictors of human-product interaction. Appl. Ergon. 43 (4), 713-726.

Ulrich, K., Eppinger, S., 2008. Product Design and Development, fifth ed. Paperback.

United Nations, 2011. World Population Prospects: the 2010 Revision, Volume I: Comprehensive Tables. Department of Economic and Social Affairs, Population Division, 2011, United Nations.

Voelz, S.L., Hunt, F.E., 1987. Measurement of hand strength in arthritic women and design of appliance control knobs. Home Econ. Res. J. 16 (1), 65-69.

Waller, S.D., Goodman-Deane, J.A., Bradley, M.D., Cornish, K.L., Clarkson, P.J., 2016 Walking Backwards to Quantify Visual Exclusion. Designing Around People: CWUAAT 2016. Springer International Publishing., pp. 117-126

WHO, 2011. World Report on Disability. World Health Organization Press, Geneva. Wilkinson, C.-R., De Angeli, A., 2014. Applying user centred and participatory design approaches to commercial product development. Des. Stud. 35 (6), 614-631.

Zitkus, E., 2017. A review of interactive technologies supporting universal design practice. In: Antona, M., Stephanidis, C. (Eds.), Universal Access in Human-Computer Interaction, 2017, Part I. Springer International Publishing, pp. $132-141$.

Zitkus, E., Langdon, P., Clarkson, P.J., 2011. Accessibility Evaluation: assistive tools for design activity in product development. In: Bartolo, In H. (Ed.), Internationa Conference on Sustainable Intelligent Manufacturing. IST Press, Leiria, pp. 659-670.

Zitkus, E., Langdon, P., Clarkson, P.J., 2013a. Inclusive Design Advisor: understanding the design practice before developing inclusivity tools. J. Usability Stud. 8 (4), $127-143$.

Zitkus, E., Langdon, P., Clarkson, P.J., 2013b. A Conceptual Client-Designer Framework: inspiring the development of inclusive design interactive techniques. In: Universal Access in Human-computer Interaction. Springer, Berlin Heidelberg. 